\title{
A new intellectual agenda
}

\section{Why is there only One Political Philosophy Today?}

The claim that the wave of Muslim migration currently flooding Europe signifies the beginning of a new era in the history of the Continent is very plausible. But what will be the nature of this era? One possibility is the gradual Islamization of Europe, that is, the fall of the Roman Empire to the Barbarians for a second time (even if the process is not complete and total); another possibility is that Europe will come to its senses and find the inner strength to overcome the crisis. In determining which of these two possibilities will prevail, considerable weight is assigned not only to the practical steps that so preoccupies Europe at present, but also, and in almost equal measure, to the Europeans' ability to justify such steps, to themselves and to others. The liberal concepts on which the European democracies were founded-let us call them collectively the "liberty and equality paradigm "'-are incapable of this, and the postcolonialist bellyaching that has accompanied them in recent decades do not allow such steps to be taken proudly and resolutely. The hesitancy, reluctance, and contrition that characterize the actions of Europeans are largely rooted in these approaches. What Europe needs now is not only new practical solutions, but a new political philosophy. One need not be a Hegelian to understand that now, more than ever; ideologies can play a decisive role in the practical arena as well.

Yet now, when we truly need them, the humanities are in steep decline in almost all universities in the West. This decline stems mainly from the fact that it is hard to make a living in those fields, especially in a capitalist society whose moving force is the accumulation of wealth, but also because too often there is no longer any real intellectual interest in them. If we focus on the field of political theory, we will see that over the past few decades, academic discourse in the field has revolved around variations, and variations of variations, of liberal democratic thought. The West's deliverance will not emerge from this discourse at this time. This crisis demands far more radical thinking, and there is no one to supply it.

After the fall of Nazism, fascism, and communism, triumphant democracy remained alone. Since democracy's philosophical foundations are themselves rooted in liberalism, debate was thus restricted to the range of interpretations that fall along the liberal spectrum. To be sure, there was, and still is, debate. Sometimes the debate is heated, but it is no different than the intense fighting between and within various small religious sects: those involved wage their battles passionately and invest vast amounts of energy in these issues, as though the world itself depends on them. Meanwhile, outside observers ask themselves: "What exactly are they fighting about? They seem so similar..."

These words are directed, first and foremost, at American conservatism, which was apparently invented as a counterweight against liberalism, and which includes neo-conservatism, a movement that is steadily winning adherents outside the United States. But is this really the rival of liberalism? The conservatives and neo-conservatives

${ }^{1}$ Mark Le Bar (2012) On liberty and equality as the two basic principles of democracy, equality and Liberty as Complements. In: Machan T (Ed.), Liberty and Equality, Hoover Institution Press, USA, pp. 97.
Volume 2 Issue I - 2018

\author{
Benjamin Brown \\ Hebrew University of Jerusalem, Israel
}

Correspondence: Benjamin Brown, Hebrew University of Jerusalem, Israel, Email benjamin.brown@mail.huji.ac.il

Received: December 08, 2017 | Published: January II, 2018

pledge allegiance to the fathers of the American Constitution and to John Stuart Mill' ${ }^{2}$. The debate between conservatives and liberals in the contemporary intellectual arena can be reduced to the question of "how far to go" with nineteenth-century liberal views. These are differences of degree, not of kind. Anyone who has heard the oratory of then-President George W. Bush, considered an all-but-terrifying arch-conservative, as he constantly declared that he and his country have come to "protect our freedom" 3 ", can immediately grasp that the debate is not between liberals and anti-liberals, but between different types of liberals. If so, liberalism has no real rival in today's intellectual arena.

\section{Why Conservatism is not an Alternative}

I have great esteem for all of those who seek shelter in the conservative and neo-conservative schools of thought, including several people who I hold in very high regard (really). Nevertheless, I personally never understood what fresh philosophical gospel they found in it, or even what its basic philosophical claim is. (Indeed, almost none of its creators in the United States were "professional" philosophers; they were mostly columnists and public intellectuals. However, anyone familiar with where the Americans have brought philosophy in other fields will shed no tears.) What substantive message is contained in the statement: "The principles are correct, but don't take them too far"? Perhaps some neo-conservatives propose additional values that are occasionally worth using to counterbalance the values of liberty and equality, but what is the philosophical justification for these values, and what are the principled criteria for balancing values? Neo-conservatives are merely liberals of the nineteenth or perhaps early twentieth century. What good can come from someone who ultimately takes the same steps, just slower? To wit, today one can find many neo-conservatives fighting for the rights of blacks, women, and even homosexuals, all in the name of America's "conservative" values! Their discourse is one of rights,

${ }^{2}$ For very occasional instances: Peter Berkowitz (2003), Constitutional Conservatism: Liberty, Self-Government, and Political Moderation. Hoover Institution Press, USA. Mark Blitz (2011) Conserving Liberty. Hoover Institution Press, USA. Russell Kirk (1985) The Conservative Mind: From Burke to Eliot. USA. Robert Nisbet (2002) Conservatism: Dream and Reality. Rutledge, USA. Charles W Dunn, J David Woodard (1996) The Conservative Tradition In America. In: Rowman Md \& Littlefield (Eds.), pp. 54-55, 123 126.

${ }^{3}$ For example: "Transcript: George Bush's speech on Iraq", The Guardian, 7.10.2002,

https://www.theguardian.com/world/2002/oct/07/usa.iraq; BBC News. 8.8.2002,

http://news.bbc.co.uk/2/hi/americas/2309049.stm 
liberty, and equality as much as that of their liberal rivals, which all but invites the challenge: If you are ultimately fighting for the same values that liberalism fought for yesterday, why wait? If these are ultimately the values of the great, enduring Truth, why hold back? If you think that yesterday's conservative stances caused injustice, why not speed up their eventual defeat by a few years and thereby prevent some of that injustice? More generally, does the great gospel simply preach: "Wait a bit longer"?? Of course, the call to carry out changes patiently, infrequently, and gradually is supported by wise reasoning and healthy common sense.

The logic of this call is greatly reinforced when one contemplates the painful experiences of the twentieth century and its whirlwind of revolutions, which transformed all of humanity into a giant laboratory for experiments on humans and sacrificed tens of millions on the altar of those experiments. And yet, sound advice is not an organized system of beliefs and values, and therefore cannot by itself be considered the foundation of a political philosophy. In such cases, conservatism contributes by instructing us "how" (how to effect changes with a minimum amount of damage), but not by teaching us "what" (what should be changed and what it is important to preserve). Therefore, when the failing paradigm is about to collapse, conservatism does not offer a real alternative.

Absent an adequate philosophical foundation, an ideology of conservatism for the sake of conservatism is non-rational and very difficult to justify. Moreover, it is tarnished by what can be termed "the Paradox of Conservatism." This paradox can be illustrated in a brief dialogue:

\section{Que: Why conservatism?}

Con:We have reached such a good place, why change?

Que:Because we got to this great place by virtue of those who wanted to change things and did not listen to the conservatives.

Conservatism is a good and proper virtue only within non-rational cultural systems, and especially religious traditions. If one believes that the (divine) truth has already been revealed, and that as we grow distant from the revelation, our knowledge of it diminishes, then the most correct thing to do is to conserve as much as possible. The strong conservative sentiment of religious leaders is thus appropriate, and they should be praised and adored for it. One should hope that this inclination continues to guide them even in the face of pressure to abandon it or render impotent the framework within which they operate.

This does not hold true for a system that purports to be rational, that believes that the great (rational) truth has not been revealed to us and maintains that free and steady criticism is the most efficient tool for its attainment. Here, conservatism does not mesh with the system's values, but rather generates tensions within it, if not outright internal contradictions. Even if, on the practical level, it is reasonable to demand that changes not be made too frequently or hastily, on the philosophical level there is a constant need to rethink and reassess existing premises.

This last demand is one of Popper's primary lessons in The Open Society and its Enemies ${ }^{4}$. Except that Popper runs into another, more popular paradox, which can be called "the Paradox of Liberalism" and which can also be illustrated with a brief dialogue:

${ }^{4}$ Karl Popper (1950) The Open Society and its Enemies. Princeton University Press, USA, pp. 398-409.
Que:Why an open society?

Lib: Because openness enables free and critical thinking, and criticism enables self-improvement.

Que:Are you willing to critique and improve the principle of openness as well?

Indeed, in this respect, Western democratic society has long ceased to be an "open society." It has become a society that champions the dogma of openness, which is essentially conservative of openness. If so, not only are the conservatives liberal, but the liberals are conservative. And so we are left with a single liberal-conservative or conservative-liberal movement, in which each party to the debate seeks to conserve liberal principles and the only thing left to argue about is the most correct or most successful interpretation of those principles. Everyone frolics within the liberty and equality paradigm, but no one thinks outside its narrow box. Political philosophy has become ossified within the regnant paradigm, as though some "rude coarse prohibition" as been imposed upon the philosophers: "Ye shall not think!'” (to paraphrase Nietzsche) ${ }^{5}$.

\section{Why a Paradigm Shift is Necessary within the State, or: Why the Party must be Broken Up}

Thus far, it would seem that everyone is satisfied. The West's democracies have attained unprecedented governmental stability and considerable economic prosperity. Above all, they have not perpetrated a single mass murder or cruelly suppressed a single uprising in their own states (perhaps they have in other states-thus the postcolonialist bellyaching-but that is a separate issue). Nobody longs for the old dictatorships, and no one is interested in new dictatorships. These dictatorships are viewed not only as past traumas, but as cautionary tales and shadows that threaten: "if you move as much as an inch from democratic principles, you will quickly fall into the abyss of totalitarianism." So who even wants to rethink democracy? Everything has worked great. Everyone benefited from the great movement of liberation (except for a few "conservatives" who shouted a bit from the sidelines). The winds of liberty and equality blew also in the interstate level: Many peoples, large as well as small, developed as well as underdeveloped, threw off the yokes of their conquerors, declared independence, and set out to forge new lives. Public international law granted them, with only a few exceptions, equal status within the family of nations. Numerous independence days were added to the calendar throughout the world. In short, the party was going.

\section{So why ruin it?}

Because, slowly but surely, signs that there are indeed some problems with the liberty and equality paradigm have begun to accumulate. Some of these problems are practical and some are theoretical, but most are a combination. Since the "liberty and equality paradigm" was imposed on bother the intrastate and inter-state levels, the signs of crisis are visible within states and at the international level. I will begin with the arena that most affects the individual's life-the intrastate arena.

As early as the first part of the nineteenth century, Tocqueville showed that the principles of liberty and equality contradict one

${ }^{5}$ Friedrich W Nietzsche (2012) Ecce Homo. Dover Publications, USA, Par II, sec 1 . 
another ${ }^{6}$. Marxism sharpened this critique from a different angle, demonstrating that, in a situation of economic freedom, the stronger party wins, and the stronger party is not necessarily the party that is better or more deserving ${ }^{7}$. Nevertheless, democracy adopted capitalism and showed that, ultimately, the prosperity that such freedom brings in its wake even benefits the weaker party more than do the restriction of freedoms through nationalized economies. The theoretical challenges were overcome by the proof in the pudding, and so calm could be restored. When it came to labor relations, it was recognized that freedom of contract is essentially the freedom of the strong to exploit the $\mathrm{weak}^{8}$, and so the freedom of contract was restricted in this sphere. And what about other spheres in which freedom was granted? Isn't greater power given to the stronger party here as well? Perhaps, but nobody cared.

During the twentieth century, when Hitler rose to power through democratic processes, it became clear that the great amount of trust that democracy places in the masses is flawed. This gave rise to the idea of "defensive" (or "self-defending") democracy", which clearly stands in tension with the principle of the people's sovereignty. What of all the theoretical presumptions about the collective wisdom of the people? By the time the practical problem was solved, the theoretical question had already been left by the wayside. In many democratic states, leaders were elected-certainly ministers, but sometimes even heads of state-which turned out to be less than reputable. When Thomas Paine sought to attack the dynastic monarchy, he marshaled as evidence those rulers who that system brings to power. Such a regime, he wrote: ...indiscriminately admits every species of character to the same authority. Vice and virtue, ignorance and wisdom, in short, every quality, good or bad, is put on the same level.... It reverses the wholesome order of nature. It occasionally puts children over men and the conceits of non-age over wisdom and experience ${ }^{10}$.

We see that the character of the rulers in these countries is "below the average of human understanding; that one is a tyrant, another idiot, a third insane, and some all three together, it is impossible to attach confidence to it, when reason in man has power to act ${ }^{11}$ ". I wonder what Paine would have said had he seen the rogue's gallery of leaders who rose to power within the past hundred years via the democratic mechanisms that he so badly wished to advance. To use only examples from the top of my head, there were tyrants (Hitler, Mussolini), wimpy defeatists (Chamberlain, Carter, Obama), a former Nazi (Waldheim), a suspected former Nazi (Helmut Schmidt), a former collaborator with the Nazis (Mitterrand), a pedophile (Edward Heath), drug abusers (Anthony Eden, JF Kennedy), an alcoholic (Boris Yeltsin), and others with varying degrees of psychological disorders (a 2006 study claims that about half of US Presidents during the nation's

\footnotetext{
${ }^{6}$ Alexis De Tocqueville (2004) Democracy in America. Library of America USA. Erik von Kuehnelt-Leddihn (2014) Liberty or Equality: The Challenge of Our Times. Mises Institute, USA.

${ }^{7}$ Karl Marx and Friedrich Engels (1970) The German Ideology. International Publishers, USA, pp. 83-84

${ }^{8}$ Otto Kahn-Freund (1977) Labor and the Law. Stevens, London, pp. 1-17.

${ }^{9}$ Raphael Cohen-Almagor (1994) The Boundaries of Liberty and Tolerance: The Struggle against Kahanism in Israel. University Press of Florida, USA, pp. 1-131. Ami Pedahtzur (2002) The Israeli Response to Jewish Extremism and Violence. Manchester University Press, England, pp. 3-11. Pauline Kuss (2014) The Principle of a Defensive Democracy in Action. Germany. Grin Verlag (2000) For applications of the doctrine. In: Raphael Cohen-Almagor (Ed.), Liberal Democracy and the Limits of Tolerance, University of Michigan Press, USA.

${ }^{10}$ Thomas Paine (1833) Rights of Man. In: Muir \& Gowans (Eds.), Scotland, pp. 60 .

${ }^{11}$ Ibid.
}

first two hundred years had some mental disorder or another) ${ }^{12}$, not to mention innumerable cases of corruption, bribe-taking, breach of trust, and embezzlement. In my tiny young country, Israel, one prime minister has been convicted of corruption, another was spared trial from similar indictments by dying, a president was spared him from a similar ordeal by resigning, and another president has been convicted of rape and now sits in jail. (This list does not include a prime minister who was forced to resign when it was discovered that his wife has a foreign bank account; that case is "small change" compared with the others.) At least we can take comfort in the fact that the crimes of democratically-elected leaders are eventually disclosed and judged (unlike in dictatorships), that they are not tyrants, and that their terms are limited. This is real comfort that should not be belittled, but again: does the existence of a painkiller absolve us from the need to cure the disease?

Moreover, there have been a series of wars in which democratic states faced tenacious non-democratic forces and lost, or at least failed to win. Democracy, which won both world wars, was exposed as weak against guerilla forces and terror ${ }^{13}$. The Western democracies comforted themselves with the fact that these wars were, perhaps, extraneous. Additionally, democracy's weakness is not limited to the sphere of foreign affairs. When many neighborhoods in Europe are off-limits to the police $(! !)^{14}$, it should serve as the alarm bell that wakes even the most complacent.

Indeed, it has woken them up, but they are not equipped with the theoretical tools necessary to justify using measures that the democratic tradition generally abhors. In such a situation, any police officer, and certainly any police superintendent, knows full well that he is better off letting crime run rampant than being accused by liberal purists of racism and police brutality ${ }^{15}$-two of the liberal code's most severe indictments. Democracy has continued to surrender to violence

${ }^{12}$ Jonathan Davidson, Kathryn Connor, Marvin S Swartz (2006) Mental illness in U.S. Presidents between 1776 and 1974: a review of biographical sources. The Journal of Nervous and Mental Disease 194: 1, pp. 47-51.

${ }^{13}$ Gil Merom (2003) How Democracies Lose Small Wars. Cambridge University Press, England, pp. 14-18, 243-259. Dan Reiter, Allan C Stam (2002) For a different opinion, democracies at War. Reiter and Stam examine wars of democratic countries in general, without segmentation of their enemies, Princeton University Press, USA.

${ }^{14}$ Laura Mowat (2016) Europe's No-Go Zones: List of 900 EU areas where police have 'lost control' to migrants. Express, USA. https://www.express. co.uk/news/world/657520/Europe-no-go-900-EU-areas-police-lost-control ; Zoie O Brien (2016) Germany No-Go Zones: Police afraid to go into lawless areas after open-door immigration. Express, USA. https:/www.express.co.uk/ news/world/729782/Germany-no-go-police-afraid-lawless-areas-migrantsrule; Jon Smith (2016) 15 Places That Are So Dangerous That Police Refuse To Go There. The Richest. Soeren Kern (2015) European 'No-Go' Zones: Fact or Fiction? Part 1: France. Gatestone Institute Website, USA. https://www. gatestoneinstitute.org/5128/france-no-go-zones; Yves Mamou (2017) No-Go Zones Now in Heart of Big Cities. Gatestone Institute Website, USA. https:// www.gatestoneinstitute.org/10404/france-no-go-zones; Soeren Kern (2015) European 'No-Go' Zones: Fact or Fiction? Part 2: Britain. Gatestone Institute Website, USA. https://www.gatestoneinstitute.org/5177/no-go-zones-britain. ${ }^{15}$ Ron Delord, John Burpo, Michael Shannon, Jim Spearing (2008) Police Union Power, Politics, and Confrontation in the 21st Century: New Challenges, New Issues. In: Charles Thimas (Ed.), Springfield, USA, pp. 250. Paddy Dinham (2016) Met Police chiefs 'are so worried about being called racist they refuse to crack down on Muslim officers with extremist views. Daily Mail, London. http:/www.dailymail.co.uk/news/article-3784113/ Metropolitan-Police-worried-called-racist-refuse-crack-extremist-views.html ; Heather Mac Donald (2015) Officer Beaten by a Convicted Felon Hesitated for Fear of Being Called Racist: Welcome to Post-Ferguson Policing. National Review, USA. http://www.nationalreview.com/article/422605/officer-beatenconvicted-felon-hesitated-fear-being-called-racist-welcome-post . 
particularly that of minorities, in other cases as well. Space does not permit a full itemization, but I will briefly note that some of them hinged on the double standards and variable application of concepts like "racism," "xenophobia," "incitement," and "provocation."

The problem of attitudes toward minorities has also generated the well-known, liberal, "melting pot" versus "salad bowl" (that is, multiculturalism) dilemma ${ }^{16}$. One can debate which of these methods has brought about better practical results, but it is incontrovertible that, on the theoretical level, they represent conflicting values from the liberal canon: the "melting pot" promotes equality and liberty by giving individuals from the minority population opportunities that approximate those available to the majority population, and by interfering with freedom-denying norms that persist within the minority community. The "salad bowl" promotes the equality of minorities by relating to their collective culture as one with as much a right to exist as the majority culture, thus allowing for complete freedom of communal incorporation and education. This freedom, however, may clash with the liberties of individuals within that group, especially when the groups systematically violate the rights of the individuals. And so, the two methods contradict each other, and therefore choosing either one of them necessarily "violates" the canonic liberal values embodied by the rejected alternative.

Liberal democracy is also very selective in the degree to which it is aware of discrimination against groups. Consider, for example, the following question: Why does liberal democracy not extend the right to vote to minors? I don't mean just youths, I mean real children ${ }^{17}$ If one answers that it is because they do not possess sufficient understanding, then why not restrict the voting rights of insufficiently understanding adults? Anyone can point to children who have more understanding than adults and adults who have less understanding than children. If one then argues that those with deficient understanding are also entitled to representation, then the question returns: why not children? Perhaps it is because children have not yet come into liberal fashion $^{18}$. It is very likely that their time will come, and equal rights for children will become a liberal trend, in the same way that the rights of blacks, women, homosexuals, and most recently animals initially gained momentum. If this were accomplished in context of an overall policy that assesses the political competency of individuals-regardless of age, color, or sex-then great. But it is reasonable to presume that even in such a case, liberals will prefer blanket automatic rights, as is their wont. Yet all this will happen when children's rights become fashionable and children become an aggressive social lobby that silences dissent, just like other previously underprivileged groups. Others, presumably, will never have the advantage of such a lobby.

${ }^{16}$ Brian Barry (2001) Culture and Equality: An Egalitarian Critique of Multiculturalism. Harvard University Press, England. Paul Kelly (2002) Multiculturalism Reconsidered: 'Culture and Equality' and its Critics. Polity Press, England.

${ }^{17}$ Sonja Grover (2011) Young People's Human Rights and the Politics of Voting Age. Springer, Netherlands.

${ }^{18}$ John Wall (2014) The calls to enable children's vote, however, are in increase. Why Children and Youth Should Have the Right to Vote: An Argument for Proxy-Claim Suffrage, Children, Youth and Environments, 24(1): 108-123; Joshua Gans (2012) Why It's Time To Give Children The Right To Vote Forbes, USA. https:/www.forbes.com/sites/joshuagans/2012/04/20/itstime-to-give-children-the-vote/\#5bef1cb4a0d3; Noah Berlatsky (2015) Give Kids the Vote! The Case for Children's Suffrage. The Pacific Standard. Bob Franklin (2010) Right to Vote: Children's Rights means Citizens' Rights. Child Rights International Network. https://www.crin.org/en/library/publications/ right-vote-childrens-rights-means-citizens-rights .
Ugly people, for example, cannot sue for as much social attention as the good-looking, and no social movement will ever rise to advance their equality. Although no law discriminates against them, they are not equal, and it seems they will never have equal opportunity to form romantic relationships, marry, find jobs, or be elected to senior public office. In this regard, they are discriminated against more than women, blacks, and homosexuals combined, yet they are so untrendy...

Indeed, no one with a healthy critical faculty can fail to recoil from the arbitrary, fashion-conscious, and somewhat self-serving character of liberal defense of rights. A liberal's generalizations about, say, evangelists will seem to him and to his fellow liberals completely legitimate, but replace Orthodox Jews with Arabs, women, or homosexuals, and the very same sentences will horrify him to the depths of his soul. In general, the liberal defends the rights of fellow liberals, just as the fascist defends fellow fascists and the religious defend others who are likewise religious, but in contrast to them, he purports to be more "open" and "inclusive." If we nevertheless find that the liberal is inclined to defend illiberal forces as well, it is only those forces that he can find at his side in protests in the city squarethat is, primarily non-Western minorities, who, in his view, will always be among society's oppressed, even if within their communities they are the greatest of oppressors.

Since we have already touched on liberal attitudes toward religion, we cannot just speed past the issue of offending religious feelings, and religion-state relations in general. Indeed, after all of the ink that has been spilled on the question of offending feelings, what did liberals ultimately decide? Are they to be protected or not? If you are a woman, yes (within the infinitely wide boundaries of the crime of sexual harassment); if you are a minority, also yes (within the wide boundaries of the sins of racism); but if you are religious, or otherwise conservative, then certainly not. If the "animal rights" trend continues to grow (such trends are becoming ever more extreme, and we will never reach the liberal's ultimate goal, for reasons I will explain on another occasion), perhaps we will win the protection of the feelings of animals. Liberals will know how to explain, using the most selfpersuasive rationales, why the feelings of quadrupeds deserve more protection than those of religious people. The only religious feelings that liberals know to take into consideration are, as usual, those of nonWestern minorities, especially if they react violently to any affront to these feelings. That type of violence, needless to say, is nothing but the natural reaction of the frustrated "oppressed" to the Western "oppression," which the Westerner should treat not only forgivingly, but also with a deep sense of guilt. Aside from such cases, a liberal relates to religion primarily as something for which doors must not be opened unless there is no choice, lest it overwhelm him and return the world to the Dark Ages.

There is no doubt that the attitude toward religion in the liberal worldview is more firmly rooted in the historical context of the eighteenth and nineteenth centuries-when religion was seen as the main threat to human liberty-than in any proper theoretical justification. Thus, for example, most democracies uphold the doctrine of "freedom from religion," some even in its more extreme version of "separation of religion and state." These doctrines negate religion's very ability to vie in the public sphere for the chance to influence legislation. No other worldview is treated in this fashion. Why is there "freedom from religion" but no "freedom from liberalism" or "freedom from vegetarianism"? Why has no doctrine of "separation 
of feminism and state," for example, emerged ${ }^{19}$ ? A liberal will offer a variety of distinctions, none of which will be anchored firmly within liberal theory itself. I am no longer speaking of the absurdities that this doctrine creates on the practical plane: A legislator may draft a law that sets certain limits for social or environmental reasons or whatnot, but he may not propose the same law with those very same limits if their motive is religious. To use an example devised by Israeli parliamentarian Dr. Yuval Steinitz: let us say that Israel adopts the doctrine of separation of religion and state as enshrined in the First Amendment of the United States Constitution. In that case, if a particularly environmentally-conscious parliamentarian proposes a bill to prohibit the importation of shrimp, out of concern for the survival of that species, the proposal can be deliberated and even become law. However, if the very same law would be proposed by a religious parliamentarian in order to strengthen the status of Jewish dietary law (which prohibits eating shellfish), it would not even be permitted to bring it up for deliberation ${ }^{20}$. To this we may add: how can a liberal know the legislator's motives? Is he a mind-reader? Of course, he will probe the character of the legislator. The limitations on legislation called "religious" are thus ad hominem to virtually the same extent that they are ad rem.

All of these internal contradictions are but the tip of the iceberg of the mess of contradictions and fallacies that surround the liberal worldview from all sides. To the best of my knowledge, the only liberal thinker who has attempted to present a theory that can help solve these problems is Prof. Alan Dershowitz, in his underappreciated Rights from Wrongs ${ }^{21}$. This book does not deal at all with the fallacies of the liberal worldview, but specifically with the source of the validity of rights. Dershowitz surveys philosophical and theological attempts to anchor basic rights in democratic society, and then refutes them one by one. He then makes his own argument: humans within a society disagree about what the goals of that society ought to be. That is, they have different answers to the question, "Where do we want to go?" On the other hand, there is a broad consensus about the inverse question: "Where do we NOT want to go?" We do not want gulags or concentration camps. This broad consensus can serve as a source for legal rights: the rights we wish to enshrine are those that will best keep us away from the injustices of evil regimes. Looking at this "from above," one can say that Dershowitz's theory is essentially the first serious attempt to apply philosophical pragmatism within the field of legal theory (I say "from above" because Dershowitz himself-who the book shows to be familiar with philosophical literature-does not mention pragmatism at all as a source for his ideas). In effect, Dershowitz proposes a theory that seeks to ground the array of liberal dogmas on a new and different foundation, and it seems that no one has yet recognized how revolutionary this theory is and the contribution it can make to the solution of the various problems emanating from democratic theory. However, in his efforts to set the liberal worldview on a new base, Dershowitz actually pulls the basis out from under all liberal dogmatism more generally. There are no longer and "natural" or "sacred" human rights. Everything is determined by the practical need to fight against ever-changing totalitarian threats. Indeed, Dershowitz's test is too fluid. There is a broad consensus that we do not want to become like ISIS, but how does that inform attitudes toward

${ }^{19}$ Daniel Statman, Gideon Sapir (2014) Dat Umedinah BeIsrael: Diyun Philosophi-Mishpati, State and Religion in Israel: Philosophical-Legal Discussion. Haifa University Press, Israel.

${ }^{20} \mathrm{https}: / / \mathrm{www}$.youtube.com/watch? $\mathrm{v}=\mathrm{G} 7 \mathrm{CWFtPModY}$

${ }^{21}$ Alan Dershowitz (2004) Rights from Wrongs: A secular Theory on the Origins of Rights. Basic Books, USA.
Muslim immigration or to the degree of liberty afforded to Islamists in European countries, for example? The answer, presumably, will not be one that a liberal purist wants to hear.

The Islamic threat is in fact the crisis that is ending the party today. As long as this threat was ephemeral, wafting over from the general direction of Islamic lands, Europeans could continue distracting themselves from their lack of action and real concern with selfcongratulatory postcolonial bellyaching. But as soon as the shock waves of this crisis reaches them and alters their social and cultural fabric, the state of their internal security, and, in the long term, their sacrosanct standard of living, and they become a persecuted majority in their own states-something begins to stir. Yet the ability to justify this change of course within the regnant paradigm of liberty and equality is extremely limited. Thus, for example, when Geert Wilders (an otherwise impressive politician and ideologue) insists on presenting his anti-Islamist platform as the direct and logical extension of the liberal worldview ${ }^{22}$, it merely exposes more of that worldview's selfcontradictions.

I wish to emphasize that the source of the crack in the "liberty and equality paradigm" is not the fear of a future Islamization of all Europe. Such an extreme scenario is unnecessary. Let us assume that Europe will not become Muslim. Let us assume that its Islamic, non-Western component does not gain control, but merely grows palpably. The results will be: poverty will spread, socioeconomic gaps will widen, taxation will be increased in an attempt to narrow those gaps, grumbling about these gaps will generate extreme unrest, since these populations have a penchant for violent protest (especially when liberal elites provide a tail wind), the police will be unable to enter ever more neighborhoods, terror will escalate on the streets, the former immigrants' parliamentary representation will grow to the point that it will be difficult to take a strong stand against them, extremist movements will arise on the right, and then an extremist left will rise as well. This scenario does not require a Muslim majority or rise to total power. Will it not suffice? This is no mere speculation, nor is it merely one possible scenario of many. Some of its elements are already playing out today.

\section{Why a paradigm shift is necessary on the international arena}

The liberal ethos won (and we all lost) on the international level as well. Since World War I, the doctrine of national self-determination, which guarantees sovereignty to any collective that answers to the name of "nation," has gained supremacy over public international ${ } \mathrm{w}^{23}$. This, of course, is the paradigm of liberty and equality applied to the international level. It, too, generates absurd situations: by virtue of the self-determination principle, any collective recognized as a nation is automatically eligible for sovereignty-a powerful and dangerous loaded weapon-and membership in the United Nations. Thus, during the seventy years of its existence, the number of member states in the UN has quadrupled. That would be fine if each of these states could fend for itself, but each week I see the mournful faces of newscasters as they report on another African nation that suffers from famine, disease, civil war, and intertribal bloodshed. (Postcolonialist liberals will explain that the white man is at fault for this as well, since

${ }^{22}$ Geert Wilders (2012) Marked for Death: Islam's War Against the West and Me. Regnery Pub, USA, pp. 22-27, 209-215.

${ }^{23}$ Thomas D Musgrave (1997) For historical development and current legal condition. Self-Determination and National Minorities, Clarendon Press, England, pp. 1-124. 
colonialism undermined the previous social and tribal order-as though such a subtle, sensitive, and finicky order can adequately address famine and plague, and as though, before colonialism, the same tribes did not murder each other without anyone taking interest.) Even if we take an apparently "stable" state like North Korea, is it really moral to respect its sovereignty? And let us not forget the Muslim world: is Syria, in its present state, eligible for sovereignty? If a coalition of Western states were to take over Syria to restore order and return it to the straight and narrow (and also curb the dangerous wave of migration to Europe), would that not be more moral than the present situation? But no Western state would dare occupy a non-Western state today, not even temporarily, and not only due to legal considerations, which forbid such intervention, but also because any war that the West enters will immediately be presented by the West's strong liberal forces (the media, the academy, etc.) as a colonialist invasion that involves the harming of innocent civilians and war crimes, and as the needless bloodletting of Western soldiers (with daily body counts in the media and all other familiar forms of propaganda). I emphasize again: I am not addressing the utilitarian justifications for such an invasion, but the principled moral question: is the Syrian nation (for example), in its present state, morally worthy of sovereignty? If there is agreement that it is not, what does this say about the legal and political theory that grants this right automatically, from the moment it is declared a "nation"? Indeed, it is not only the problem of Syria that must be solved, but the problems of an amoral theory that granted Syria the loaded weapon called "sovereignty" and this brought about this mass loss of human life and property. Even if, at some point in its past, Syria was worthy of sovereignty, it lost that right, and had the international system been based on moral principles, it would not have hesitated to revoke its right, even after it had already gained independence. Even if the system would take political constraints under greater consideration, it would permit massive intervention in Syria, which anyway no longer behaves like a sovereign state.

To overcome problems like Syria, perhaps jurists of the future will invent additional qualifications and grounds for relaxing the rules of military non-intervention, just as they invented new doctrines to limit the wild over-application of the principles of equality and liberty within states. But the attempts to solve the practical problems that reality poses to the liberal worldview by inventing more and more qualifications, balances, and euphemisms is quite reminiscent of the attempts to rescue the geocentric model by adding more and more complicating factors and contrivances to the laws of motion of heavenly bodies around the earth. Like then, the regnant theory may perhaps be salvaged for a while, but its persuasive power will steadily decrease, and a harsh sense of intellectual discomfort will pervade. This is the sense that heralds the need for a paradigm shift. I have used the future tense, but in truth, this sense already exists within Western civilization, and anyone with critical faculties can detect it. The time has come, then, to propose a new paradigm.

\section{Justice and Areté-toward an Inequality-based Paradigm}

What is the proper direction for this paradigm to take? It goes without saying that a short essay like the present one does not sufficiently permit the development of its necessary direction. Nevertheless, we cannot let ourselves off scot-free, so I will present a preliminary sketch, and maybe not even that much, to show that this is not an empty proposal. But before presenting it, I must preface it with two reservations:
First, the reader may be disappointed (or perhaps pleasantly surprised) that even after the scathing criticism above; I ultimately remain faithful to most institutions and principles of the contemporary democratic state. I do not wish to return to dictatorships, and I can appreciate the value of subjecting government to criticism and limiting its power. Changing the paradigm should not create revolution (certainly not of the sudden and violent sort) or install a completely different sort of regime. The primary objective of this exercise is to create new categories of thought, by means of which political and legal calculations can be made even within the existing system.

Second, more than I seek to propose a full-blown theory, I want to propose a new direction of thought. But most of all, I am issuing a call: instead of investing intellectual efforts to further qualify or complicate the regnant paradigm, invest them in the search for a new paradigm. If a reader, or anyone else, finds a better paradigm than the one I am suggesting, it would be wonderful. In other words, more than I am offering new theoretical content, I am proposing a new intellectual agenda.

To understand the root of the difference between the new agenda and liberal theory, let us imagine two people who survive a shipwreck and each reach a different desert island. Both realize quite quickly that there is little chance of being rescued in the near future and that they can expect to spend a long time on the island. Faced with this realization, each behaves differently: One scouts the island and explores its natural treasures. He learns where fruit and other edible plants grow. He gathers material to build himself shelter. He learns to make primitive tools and uses them to make more tools. Once he manages to create writing implements, he writes to himself. He tries to produce fire so he can signal to passing aircraft. Gradually, he produces works of art for himself-paintings, statues, and musical instruments. The second survivor, in contrast, responds differently. He scours the island for narcotic plants. When he finds them, he concocts drugs and then consumes them, hoping to distract himself from his predicament and die quickly and peacefully. Thus, he slides into an extended "trip," which detaches him from reality and welcomes him into the uninterrupted tranquility of an illusory world.

According to the liberal view, it is impossible to deem either of these two men to be better than the other. Both live on desert islands and so do not harm anyone else-if only because there is no one else to harm-and so cannot perpetrate any evil. According to the proponents of the "Harm Principle", their attitudes toward themselves and their own lives are a personal matter, which no one has a right to judge, at least on the socio-political level ${ }^{24}$. According to the approach I wish to advance, not only is the first survivor better, but the comparison itself is intolerable. This approach has no name, but since it originates with the Greeks, who held Areté in high regard (Areté-ỏpetń-is a difficult word to translate, combining "virtue," "excellence," and "high quality" $)^{25}$, perhaps we can call it "the Justice and Areté paradigm."

There is no way to prove the Justice and Areté paradigm, just as there is no way to prove the liberty and equality paradigm. Both depend on the most basic axioms about human concepts of good and evil. The basic premise of the Justice and Areté paradigm is that our

${ }^{24}$ John Stuart Mill (2008) On Liberty and Other Essays. Oxford University press, England, pp. 83-92. Mill believed we should definitely judge such behaviors on the personal level, but other, more pluralistic proponents of this theory went beyond its author.

${ }^{25}$ Liddel and Scott's (1925) Greek-English Lexicon. Clarendon Press, defines it as "Goodness, excellence of any kind, 1: 238. Werner Jaeger (1962) The Ideals of Greek Culture. In: Gilbert Highet, Oxford University Press, USA, 1: 3-14. 
goal during our time in this world is not to "not harm others," but to improve or develop the world a little bit, each person within his small sphere. In that sense, not all men are equal. Some improve the world more, some less, and the claim that not all people have the same opportunities to prove themselves is only of limited efficacy. When the time comes for a scientist to give an accounting of his life, he can say: "I improved our understanding of the universe"; a physician can say: "I advanced public health"; a carpenter can say: "I improved the quality of furniture"; a janitor can say: "I made conditions more sanitary." They are not equal, because people are not equal and their contributions are not equal (indeed, Einstein contributed more to humanity than John Doe the janitor), but they share an equality that does not extend to a druggie who gets hooked on his illusions and advances nothing, even if he never harms his fellow man. A society that views him as being equal to them is a society with a skewed view of the world. A society that gives him the same rights it gives them is a society that perpetrates injustice.

This leads us to a political-philosophical conclusion: If each individual is obligated to improve the world according to his or her ability and talents, it cannot be that one of the strongest, if not the strongest, social instruments created by modern man-the stateremains indifferent to this duty. On the international level, if each state is obligated to improve the world according to its power and level of development, it is inconceivable that one of the most robust global apparatuses that modern man has created-international law-stays away from such considerations.

The philosophical premise of the Justice and Areté paradigm is that, at their root, rights, liberties, and other social benefits should not be granted automatically. Thus, freedom is not automatic, and there are no "innate" or "natural" substantive rights. Granting rights and privileges unconditionally and free of charge is an affront to the principle of justice. In principle (and I emphasize, this is only on the theoretical plane), man should be born without the right of freedom or any other basic right; only after he has proven that he is worthy of such rights should society grant him them. This is technically impossible, though, because a person cannot prove himself when he has not been granted the freedom to do so. On the practical level, therefore, we are left with the right of freedom, but with a changed perspective in two respects: on the theoretical plane, freedom is not a substantive and sacred right, but one that results from technical constraints. On the practical plane, rights and freedoms are granted only to the extent that they are necessary to allow a person to prove himself and his Areté. Once he has demonstrated the opposite, restricting his rights is justified. Criminals, junkies, and bums cannot appeal to society in the name of "rights," only, if anything, in the name of grace and compassion.

Areté is not about equality, but about justice. Justice means giving more to whoever deserves more and giving less to whoever deserves less. Those who deserve more are those of greater Areté and those who deserve less are those of lesser Areté. This applies not only to the allocation of goods, but also to the allocation of other "pleasures" such as rights and liberties. The Justice and Areté paradigm therefore argues that Justice precedes liberty and equality not only on the normative level, but also on the logical level.

This leads us to a major question: who determines what is Areté? Even if there would be a consensual standard, who decides who has attained this level, and to what degree? Quis custodiet ipsos custodies? These questions, which, there is no denying, are indeed challenging, can be lumped together and termed the "feasibility question." Every political theory is subject to such a question. Even the classic thinkers of liberal democracy addressed it to some limited sense, and it was the democratic regimes themselves which constantly grappled with it, even while forging institutions and arrangements in responseresponses that were not always satisfactory. The feasibility question does not eliminate the moral requirement to accept the Justice and Areté paradigm. Rather, it intensifies the call I issued above: Direct intellectual resources to address the questions emerging from new paradigms, instead of tiptoeing around the old ones that are barely functioning.

Let us presume for a moment that a certain society has determined exactly which values constitute Areté in its eyes, as well as the hierarchy of those values. Let us further presume that this array of values is philosophically justifiable. In such a case, it is conceivable that it will be feasible to create transparent and objective (to the degree possible) judicial mechanisms for determining who has achieved these values, and to what degree. No doubt, such a mechanism poses problems, but it is not very different from other mechanisms that democratic society developed to judge and classify citizens for purposes that it deems legitimate: for instance, various appointments committees, or committees that award prizes and grants in the arts and other fields with no objective indices. If this proves impossible, or if the mechanisms quickly descend into corruption, we will be forced to adhere to the value of equality as presently applied-not because it is sacred, but because there is no choice. Recognizing that this is its raison d'être will certainly-and fortunately-impact its aura of sanctity in the cultural, legal, and political spheres.

As noted, the principles of Justice and Areté will not only apply to the status of the citizen within the state, but to the status of collectives within the international system. The Areté of collectives, that which grants them the right to sovereignty, is the development of state infrastructure on the social, political, economic, educational, legal, diplomatic, and even moral levels-the infrastructure that enables these collectives to endure responsibly and function properly within the family of nations.

Here, too, it would be insane to leave the determination of this right to a body in which all states are equal, like the UN General Assembly. This body is flagrantly immoral, not only because the votes of Tuvalu and Kiribati are of equivalent to those of the United States and China, despite the massive differences between them in size and population. Even more disturbing is the fact that Syria's vote is equivalent to that of the Netherlands or Denmark, and North Korea's equivalent to South Korea's, despite the massive differences between them in terms of moral eligibility for sovereignty.

Changing methods of assessment in the international arena will not only alter the criteria for future recognition of states, but will also change our view of the past (and of course, the view of the past influences present and future political behavior). In light of the Justice and Areté paradigm, the colonialist project, though responsible for a series of terrible injustices toward its subalterns, was not necessarily morally unjust in and of itself. Especially noteworthy in this context is the mandate system, adopted at the time by the League of Nations ${ }^{26}$ and always (correctly) considered a form of soft or

${ }^{26}$ Frederick Pollock (1920) The League of Nations. Stevens, London, pp. 177180. Susan Pedersen (2015) The Guardians: The League of Nations and the Crisis of Empire. Oxford University Press, England. Martyn Houdsen (2014) The League of Nations and the Organization of Peace. Routledge, USA, pp. 86-88. 
disguised colonialism. The idea underlying it is similar to the idea of guardianship in private law: the colonial power does not receive full and permanent control over the occupied colony, but only a "mandate" to advance that country, preparing it for independence. The era of the mandate system did not last long, inter alia because colonialism as a whole collapsed like a house of cards in the face of the new global zeitgeist. Nevertheless, their failure does not require us to regard them as fundamentally morally flawed. At most, its implementation was flawed, as was that of the entire colonial project. Indeed, it is highly doubtful that any world power today would want to reassert control over distant colonies and yoke the necks of Islamic and African countries back to the millstone. Therefore, the practical ramifications of the Justice and Areté paradigm on the international plane will be limited and will focus primarily on slowing the dizzying pace of proliferation of independent states. But here too, the shift in consciousness is significant, not just the practical elements. The time has come to put an end to postcolonialist bellyaching, especially since yesterday's victim has become today's aggressor. Only liberals still insist on viewing him as a perpetual victim, because of their conclusive presumption-irrebuttable and unrelated to facts-that the non-Western side is always the victim, and the Western side is always the aggressor and the enslaver.

\section{Out with the Old and in with the New - but not too Much}

As we have seen, the Justice and Areté paradigm ultimately enshrines most of the rights and institutions of the present democratic regime, even if it views them as technically necessary for proper assessment of Areté, not as substantive or sacred ("self-evident truths" in the pseudo-philosophical and baseless claim of the framers of the United States Declaration of Independence). Still, a change in rights discourse can have intellectual implications for attitudes toward those rights, and even some practical consequences for the way in which those rights are implemented. Other aspects of democracy, especially those that do not pertain directly to the values of equality and automatic freedom, can and should be preserved and protected. In the final analysis, liberal democracy gave us not only curses, but also-perhaps mainly-wonderful blessings and no fair-minded or benevolent regime should relinquish those great gifts. Among them, I will mention four especially important principles (presumably there are more), that do not pertain directly to the values of liberty and equality: (A) rule of law (including the rule of law over legislature);
(B) checks and balances, including institutionalized oversight of ruling authorities; (C) elections-the possibility of replacing a government in an organized, periodic voting process; (D) freedom of migration (by this I mean the right to freely leave the state, not the unlimited right to enter it). Among the basic rights recognized today, I think that this is the only right that should be seen a substantive and not technical, that is, a "sacred" right, irrespective of Areté. One who does not want to play by the rules of the game may leave whenever he wishes, regardless of his personal qualities or the degree to which he contributes to society or to the world.

Thus, the Justice and Areté paradigm does not call for revolution, and certainly not for violent or rapid revolution. Aside from the fact that such a revolution would not be justified, it would also be likely to inflict instability on the West-the last thing it needs today. Therefore, it strives to leave the Western regimes as they are, and even to strengthen them, but also to alter the theoretical basis upon which they are founded and amend several norms that are derived from that basis. It must be conceded that the theoretical premises of the proposed paradigm are radical, but the practical consequences of those premises are not. However, the very existence of a new paradigm will perforce lead to the rethinking of the implementation of principles and functionality of institutions, and especially to the way to address all of those global social forces that pose a real threat both to the present sociopolitical order and to cultured civilization. It will provide the first response to these challenges from outside the flaccid liberal paradigm that has been with us since the nineteenth century. Opponents of liberalism can find a real ideological alternative in this paradigm, one that will be far more persuasive than futile attempts to anchor their worldview within the liberal conception itself. Needless to say, within this paradigm it will be easier to deal with the questions of how to handle the social and political questions that plague the West, and specifically Europe, right now. Of course, the new paradigm is not devoid of problems, but, as noted, it can overcome them if we initially adopt it not as a plan for immediate implementation, but first and foremost as a new intellectual agenda, a new framework in which to think, create, and discuss.

\section{Acknowledgment}

None.

\section{Conflict of Interest}

None. 